\title{
High-flow oxygen therapy for the management of patients with acute exacerbation of cystic fibrosis
}

\author{
Arnaud W. Thille ${ }^{1,2}$, Florent Joly ${ }^{1,2}$, Nicolas Marjanovic ${ }^{2,3}$, Jean-Pierre Frat ${ }^{1,2}$ \\ ${ }^{1}$ CHU de Poitiers, Réanimation Médicale, Poitiers, France; ${ }^{2}$ INSERM CIC 1402 - ALIVE, Université de Poitiers, faculté de Médecine et Pharmacie, \\ Poitiers, France; ${ }^{3} \mathrm{CHU}$ de Poitiers, Service d'Accueil des Urgences, Poitiers, France \\ Correspondence to: Arnaud W. Thille. Réanimation Médicale, CHU de Poitiers, 2 rue la Milétrie, 86021 Poitiers Cedex, France. \\ Email: aw.thille@gmail.com. \\ Provenance: This is an invited Editorial commissioned by Section Editor Guo-Wei Tu, MD, PhD (Department of Critical Care Medicine, Zhongshan \\ Hospital, Fudan University, Shanghai, China). \\ Comment on: Sklar MC, Dres M, Rittayamai N et al. High-flow nasal oxygen versus noninvasive ventilation in adult patients with cystic fibrosis: a \\ randomized crossover physiological study. Ann Intensive Care 2018;8:85.
}

Submitted Nov 20, 2018. Accepted for publication Nov 27, 2018.

doi: $10.21037 / \mathrm{atm} .2018 .11 .67$

View this article at: http://dx.doi.org/10.21037/atm.2018.11.67

Cystic fibrosis is an autosomal recessive genetic disease that provokes dysfunction of the cystic fibrosis transmembrane conductance regulator (CFTR). The disease occurs most often from birth and affects mainly the lungs. This protein dysfunction directly provokes thick mucus into bronchi promoting pulmonary infections and leading to development of chronic obstructive pulmonary disease (COPD), followed by chronic respiratory failure. Cystic fibrosis also affects intestinal function, leading to pancreatic insufficiency and malnutrition that may alter muscular function and worsen respiratory failure. Its evolution is marked by iterative episodes of acute-on-chronic respiratory failure with hypercapnia.

\section{Noninvasive ventilation: the usual treatment for acute exacerbation of cystic fibrosis}

Although there exists no specific guidelines to be applied in this setting, the patients with cystic fibrosis experiencing acute exacerbation are commonly treated by noninvasive positive pressure ventilation (NIV). Among 36 adult and pediatric experienced centers, a French survey has shown that all of them used NIV as first-line treatment in management of patients with acute respiratory failure (1). NIV is also commonly continued at home in stable patients with persistent hypercapnia, even without respiratory acidosis (1). Indeed, though pooling of all randomized controlled trial it has been found that NIV may be useful in stable patients for airway clearance complementarily to chest physiotherapy and that it may improve gas exchange during sleep as compared to standard oxygen in the most severe patients (2). However, the impact of NIV on pulmonary exacerbations and disease progression remain unclear.

Unlike cases involving patients with cystic fibrosis, the continuation of NIV at home in patients with usual form of COPD (tobacco related) and without sleep apneas remains debated (3-5). By contrast, the beneficial effects of NIV as a means of reversing acute respiratory failure in COPD patients are well-demonstrated (6-8). NIV reduces respiratory rate, hypercapnia and the sensation of dyspnea by decreasing work of breathing and by improving alveolar ventilation. NIV reduces the need for intubation and, all in all, it improves survival of COPD patients admitted to intensive care unit (ICU) for acute hypercapnic respiratory failure. Recent European/American clinical practice guidelines have strongly recommended NIV for COPD patients with acute respiratory failure, but only in case of respiratory acidosis $(\mathrm{pH} \leq 7.35)$ (9). Whereas NIV is not recommended as a means of preventing the development of respiratory acidosis in common forms of COPD with stable hypercapnia, it is routinely used at home in patients with cystic fibrosis as a means of preventing acute exacerbation $(1,2)$. 


\section{High-flow nasal cannula oxygen therapy (HFOT) versus noninvasive ventilation (NIV) in adult patients with cystic fibrosis: results from a randomized crossover physiological study}

HFOT is an oxygen technique offering greater comfort and more efficient oxygenation than standard oxygen (10). HFOT is increasingly used, particularly in patients with acute hypoxemic respiratory failure (11). A large randomized controlled trial has found that mortality of patients with acute hypoxemic respiratory failure was lower when they were treated with HFOT than with standard oxygen or NIV (10). However, to date, no randomized controlled trial has been conducted in COPD patients or in patients with cystic fibrosis.

In a recent issue of Annals of Intensive Care, Sklar and colleagues have compared NIV versus HFOT in adult patients admitted to respiratory ward for acute exacerbation of cystic fibrosis (12). In this physiological prospective crossover study performed in a single center in Canada, 15 patients who had been stabilized over median 3 days under NIV were included. They received in random order 30 minutes of HFOT and 30 minutes of NIV with a washout period of 10 minutes under standard oxygen between the two strategies of oxygenation and at the end of the study. Patient effort was estimated using diaphragm ultrasound by measuring diaphragm thickening fraction (TFdi) as a surrogate measure for work of breathing (13). All patients had obstructive spirometric pattern; the ratio of forced expiratory volume in $1 \mathrm{~s}$ (FEV1) to forced vital capacity (FVC) was $45 \%$ in median (IQR, $42-52 \%$ ), and FEV1 was $800 \mathrm{~mL}$ (IQR, $600-1,000 \mathrm{~mL}$ ), i.e., $24 \%$ (IQR, 20-26\%) of predicted volume. Body mass index was $19 \mathrm{~kg} / \mathrm{m}^{2}$ (IQR, $17-22 \mathrm{~kg} / \mathrm{m}^{2}$ ) and $73 \%$ of patients had pancreatic insufficiency. At admission, $\mathrm{pH}$ was $7.39 \mathrm{mmHg}$ (IQR, 7.38-7.41 mmHg) and $\mathrm{PaCO}_{2}$ was $53 \mathrm{mmHg}$ (IQR, $49-63 \mathrm{mmHg}$ ).

As compared to baseline, HFOT set with a flow of $45 \mathrm{~L} / \mathrm{min}$ (IQR, $45-55 \mathrm{~L} / \mathrm{min}$ ) and $\mathrm{FiO}_{2}$ of $30 \%$ (IQR, $25-$ $35 \%$ ), significantly reduced respiratory rate from 21 (IQR, 17-26) breaths per minute to 18 (IQR, 13-20) and minute ventilation from $6.9 \mathrm{~L} / \mathrm{min}$ (IQR, $5.3-11.5 \mathrm{~L} / \mathrm{min}$ ) to $5.0 \mathrm{~L} / \mathrm{min}$ (IQR, 4.2-6.6 L/min). HFOT even increased tidal volumes as compared to NIV delivered with an inspiratory positive airway pressure (IPAP) of $14 \mathrm{cmH}_{2} \mathrm{O}$ (IQR, $12-18 \mathrm{cmH}_{2} \mathrm{O}$ ) and an expiratory positive airway pressure (EPAP) of $6 \mathrm{cmH}_{2} \mathrm{O}$ (IQR, 6-6 $\mathrm{cmH}_{2} \mathrm{O}$ ). Despite low dyspnea score at baseline, comfort was better with both HFOT and NIV compared with standard oxygen. No changes were observed for pulse oximetry, transcutaneous $\mathrm{CO}_{2}$ measurements or patient effort, which was estimated by diaphragm thickening fraction measured with ultrasound. The authors concluded that HFOT was associated with decreased work of breathing per minute as compared to standard oxygen since patient effort per breath, as assessed by TFdi, remained similar regardless the oxygenation device used, while a lower respiratory rate was observed with HFOT. These findings suggest that HFOT may be the most comfortable oxygenation strategy and may decrease the respiratory rate and work of breathing as compared to standard oxygen similarly to NIV. Although measurement of work of breathing using ultrasound is not the reference method and remains debatable (13), comfort improvement and reduction in respiratory rate are two beneficial effects of major interest for patients frequently needing prolonged sessions of NIV at home or at hospital in case of acute exacerbation. In this study, $60 \%$ of patients had NIV at home prior to admission and $80 \%$ had oxygen. Consequently, HFOT may be considered as a particularly useful for these patients.

\section{High-flow oxygen therapy in COPD and hypercapnic patients: what is the future?}

As compared to standard oxygen, HFOT improves oxygenation and decreases respiratory rate and work of breathing in patients with acute hypoxemic respiratory failure $(14,15)$. Interestingly, the higher the baseline $\mathrm{PaCO}_{2}$, the greater the reduction in work of breathing (14). Moreover, minute ventilation decreases without change in $\mathrm{PaCO}_{2}$ meaning that continuous washout of dead space in the upper airway may be the main factor contributing to decrease work of breathing. The other factor that may contribute to decrease work of breathing is the positive endexpiratory pressure (PEEP) effect generated by continuous delivery of high airflow. This effect may decrease work of breathing as NIV did, especially in COPD patients with dynamic hyperinflation and intrinsic PEEP. However, the PEEP level generated with HFOT does not exceed 2-3 $\mathrm{cmH}_{2} \mathrm{O}$ even with a flow rate of $50 \mathrm{~L} / \mathrm{min}$ (16), and continuous washout of dead space in the upper airway seems to be the main factor contributing to decreased patient respiratory effort.

In a population of stable COPD patients, a physiologic study has found that the higher the airflow rate, the greater the reduction in $\mathrm{PaCO}_{2}$ while added leakage further 
decreased $\mathrm{PaCO}_{2}$ and increased pressure in the upper airway had no effect (17). Finally, a recent physiological study including stable COPD patients showed that HFOT significantly decreased work of breathing as compared to standard oxygen, although this reduction was less than with NIV (18). Patient respiratory effort as assessed by measurement of diaphragmatic pressure time product with an esophageal and gastric catheter, was $283 \pm 82 \mathrm{cmH}_{2} \mathrm{O} \cdot \mathrm{s} / \mathrm{min}$ with standard oxygen and decreased to $157 \pm 57$ with HFOT set at $30 \mathrm{~L} / \mathrm{min}$ open mouth, $143 \pm 49$ with HFOT closed mouth, and further decreased to $102 \pm 43$ with NIV (18).

Although beneficial effects of HFOT have been reported in several physiological studies, no randomized controlled trial to date has compared HFOT versus standard oxygen or NIV in COPD patients with acute exacerbation. Only observational studies in patients of mild severity $(19,20)$ or case reports in patients with acute respiratory failure who did not tolerate NIV have reported efficacy of HFOT as a means of reversing respiratory acidosis $(21,22)$. In a recent randomized controlled trial comparing HFOT with NIV in more than two hundred patients admitted at emergency room for acute respiratory failure of various origin, nearly half of included patients had underlying COPD or hypercapnia at inclusion (23). In this study, the use of HFOT was non-inferior to NIV with an intubation rate of $7 \%$ with HFOT versus $13 \%$ with NIV, suggesting that HFOT may be as effective as NIV. HFOT may be an alternative not only to NIV in case of intolerance or inability to carry out NIV, but also and especially an alternative to standard oxygen with the aim of improving comfort while decreasing NIV duration and the risk for intubation. In a recent pilot study, HFOT use improved comfort during breaks off NIV without modifying total NIV duration (24). However, a large French multicenter randomized controlled trial will soon begin with the aim of comparing the effect of HFOT or standard oxygen between NIV sessions on the number of ventilatorfree days at day 28 in COPD patients admitted to ICU for acute hypercapnic respiratory failure (25). The hypothesis of this study is that HFOT may decrease the duration of mechanical ventilation, i.e., the duration of NIV and/or the risk for intubation.

The study by Sklar and colleagues shows beneficial effects of HFOT in patients with cystic fibrosis as compared to standard oxygen and NIV. These patients are frequently treated with long term oxygen therapy and prolonged sessions of NIV, and the beneficial effects observed in this study on comfort and respiratory rate with HFOT could be provide a new oxygenation strategy for management of these patients.

\section{Acknowledgements}

None.

\section{Footnote}

Conflicts of Interest: AW Thille reports to have received travel expenses coverage to attend scientific meetings from Fisher \& Paykel, Covidien, Maquet, and General Electrics, and no personal income from any company; JP Frat reports to have received consulting fees from Fisher \& Paykel; the other authors have no conflicts of interest to declare.

\section{References}

1. Fauroux B, Burgel PR, Boelle PY, et al. Practice of noninvasive ventilation for cystic fibrosis: a nationwide survey in France. Respir Care 2008;53:1482-9.

2. Moran F, Bradley JM, Piper AJ. Non-invasive ventilation for cystic fibrosis. Cochrane Database Syst Rev 2017;2:CD002769.

3. Struik FM, Sprooten RT, Kerstjens HA, et al. Nocturnal non-invasive ventilation in COPD patients with prolonged hypercapnia after ventilatory support for acute respiratory failure: a randomised, controlled, parallel-group study. Thorax 2014;69:826-34.

4. Köhnlein T, Windisch W, Kohler D, et al. Noninvasive positive pressure ventilation for the treatment of severe stable chronic obstructive pulmonary disease: a prospective, multicentre, randomised, controlled clinical trial. Lancet Respir Med 2014;2:698-705.

5. Murphy PB, Rehal S, Arbane G, et al. Effect of Home Noninvasive Ventilation With Oxygen Therapy vs Oxygen Therapy Alone on Hospital Readmission or Death After an Acute COPD Exacerbation: A Randomized Clinical Trial. JAMA 2017;317:2177-86.

6. Brochard L, Mancebo J, Wysocki M, et al. Noninvasive ventilation for acute exacerbations of chronic obstructive pulmonary disease. N Engl J Med 1995;333:817-22.

7. Lightowler JV, Wedzicha JA, Elliott MW, et al. Noninvasive positive pressure ventilation to treat respiratory failure resulting from exacerbations of chronic obstructive pulmonary disease: Cochrane systematic review and metaanalysis. BMJ 2003;326:185.

8. Osadnik CR, Tee VS, Carson-Chahhoud KV, et al. 
Non-invasive ventilation for the management of acute hypercapnic respiratory failure due to exacerbation of chronic obstructive pulmonary disease. Cochrane Database Syst Rev 2017;7:CD004104.

9. Rochwerg B, Brochard L, Elliott MW, et al. Official ERS/ ATS clinical practice guidelines: noninvasive ventilation for acute respiratory failure. Eur Respir J 2017;50:1602426.

10. Frat JP, Thille AW, Mercat A, et al. High-flow oxygen through nasal cannula in acute hypoxemic respiratory failure. N Engl J Med 2015;372:2185-96.

11. SRLF Trial Group. Hypoxemia in the ICU: prevalence, treatment, and outcome. Ann Intensive Care 2018;8:82.

12. Sklar MC, Dres M, Rittayamai N, et al. High-flow nasal oxygen versus noninvasive ventilation in adult patients with cystic fibrosis: a randomized crossover physiological study. Ann Intensive Care 2018;8:85.

13. Vivier E, Mekontso Dessap A, Dimassi S, et al. Diaphragm ultrasonography to estimate the work of breathing during non-invasive ventilation. Intensive Care Med 2012;38:796-803.

14. Mauri T, Turrini C, Eronia N, et al. Physiologic Effects of High-Flow Nasal Cannula in Acute Hypoxemic Respiratory Failure. Am J Respir Crit Care Med 2017;195:1207-15.

15. Delorme M, Bouchard PA, Simon M, et al. Effects of High-Flow Nasal Cannula on the Work of Breathing in Patients Recovering From Acute Respiratory Failure. Crit Care Med 2017;45:1981-8.

16. Parke RL, Eccleston ML, McGuinness SP. The effects of flow on airway pressure during nasal high-flow oxygen therapy. Respir Care 2011;56:1151-5.

17. Bräunlich J, Mauersberger F, Wirtz H. Effectiveness of nasal highflow in hypercapnic COPD patients is flow and

Cite this article as: Thille AW, Joly F, Marjanovic N, Frat JP. High-flow oxygen therapy for the management of patients with acute exacerbation of cystic fibrosis. Ann Transl Med 2018;6(Suppl 2):S113. doi: 10.21037/atm.2018.11.67 leakage dependent. BMC Pulm Med 2018;18:14.

18. Pisani L, Fasano L, Corcione N, et al. Change in pulmonary mechanics and the effect on breathing pattern of high flow oxygen therapy in stable hypercapnic COPD. Thorax 2017;72:373-5.

19. Lee MK, Choi J, Park B, et al. High flow nasal cannulae oxygen therapy in acute-moderate hypercapnic respiratory failure. Clin Respir J 2018;12:2046-56.

20. Kim ES, Lee H, Kim SJ, et al. Effectiveness of high-flow nasal cannula oxygen therapy for acute respiratory failure with hypercapnia. J Thorac Dis 2018;10:882-8.

21. Lepere V, Messika J, La Combe B, et al. High-flow nasal cannula oxygen supply as treatment in hypercapnic respiratory failure: a case report. Am J Emerg Med 2016;34:1914.e1-2.

22. Plotnikow G, Thille AW, Vasquez D, et al. High-flow nasal cannula oxygen for reverting severe acute exacerbation of chronic obstructive pulmonary disease: A case report. Med Intensiva 2017;41:571-2.

23. Doshi P, Whittle JS, Bublewicz M, et al. High-Velocity Nasal Insufflation in the Treatment of Respiratory Failure: A Randomized Clinical Trial. Ann Emerg Med 2018;72:73-83.e5.

24. Spoletini G, Mega C, Pisani L, et al. High-flow nasal therapy vs standard oxygen during breaks off noninvasive ventilation for acute respiratory failure: A pilot randomized controlled trial. J Crit Care 2018;48:418-25.

25. Ricard JD, Dib F, Esposito-Farese M, et al. Comparison of high flow nasal cannula oxygen and conventional oxygen therapy on ventilatory support duration during acute-onchronic respiratory failure: study protocol of a multicentre, randomised, controlled trial. The 'HIGH-FLOW ACRF' study. BMJ Open 2018;8:e22983. 